\title{
APRENDIZAGEM SIGNIFICATIVA DE ANÁLISE COMBINATÓRIA PAUTADA NOS TRABALHOS EM GRUPO E NA COMUNICAÇÃO MATEMÁTICA
}

\author{
MEANINGFUL LEARNING OF COMBINATORIAL ANALYSIS BASED ON \\ GROUP WORK AND MATHEMATICAL COMMUNICATION
}

\author{
Keli Jacoby \\ Rede Estadual de Santa Catarina \\ keli_pzo@unochapeco.edu.br \\ Rosane Rossato Binotto \\ Universidade Federal da Fronteira Sul - UFFS \\ rosane.binotto@uffs.edu.br
}

\section{Resumo}

Este artigo apresenta um recorte de atividades presentes na dissertação de Jacoby (2019), e tem como objetivo analisar as possíveis contribuições para aprendizagem significativa de Análise Combinatória a partir da realização de atividades em grupo, explorando a comunicação matemática. Para tanto, foi desenvolvida uma pesquisa em uma turma de $2^{\circ}$ Ano do Ensino Médio, de uma escola pública de Chapecó, SC, que iniciou com os alunos resolvendo, em pequenos grupos, situações-problema envolvendo conteúdos de Análise Combinatória utilizando apenas seus conhecimentos prévios, os princípios fundamentais da contagem, e na sequência houve, por parte da professora, a explanação desses conteúdos. Trata-se de uma pesquisa de natureza qualitativa em que a coleta de dados ocorreu a partir de testes e questionário aplicados nos encontros, anotações em diário de bordo e material escrito pelos alunos. A análise dos dados realizada por meio de categorias textuais evidencia que esta proposta contribuiu de forma significativa para a aprendizagem de Análise Combinatória, pois os alunos apresentaram avanços na capacidade de resolver problemas de contagem. Além disso, os resultados obtidos sugerem que as discussões em grupos, com estímulo à argumentação, trouxeram contribuições para o desenvolvimento do pensamento combinatório.

Palavras-chave: Trabalho em Grupo. Comunicação Matemática. Arranjo. Permutação. Combinação.

\begin{abstract}
This paper presents excerpts of activities from Jacoby's dissertation (2019), and have that aim to analyze the possible contributions to learning Combinatorial Analysis based on group activities, exploring mathematical communication. For this, a research was developed in a class of 2 nd year of high school, from a public school in Chapecó, SC, that started with the students solving, in small groups, problem-situations involving contents of Combinatorial Analysis using only their previous knowledge, the fundamental principles of counting, and then there was, from the teacher, the explanation of these contents. It is a qualitative research in which data collection took place using tests and questionnaire applied at the meetings, notes in the logbook and material written by the students. The analysis of the data performed through textual categories shows that this proposal contributed significantly to the learning of Combinatorial Analysis, as the students presented
\end{abstract}


advances in the ability to solve problems involving counting. In addition, the results obtained indicate that exercising in groups, with stimulus to argument, brought contributions to the development of combinatorial thinking.

Keywords: Group work. Mathematical Communication. Arrangement. Permutation. Combination.

\section{INTRODUÇÃO}

Quem vivencia a realidade da sala de aula na Educação Básica tem notado algumas dificuldades na aprendizagem de Análise Combinatória. Em vários momentos alunos que normalmente possuem boas notas em Matemática, quando se deparam com esse assunto acabam não obtendo êxito.

De acordo com Vazquez (2004), a Análise Combinatória é um ramo da Matemática que permite que se escolha, arrume e conte o número de elementos de determinado conjunto, sem que haja necessidade de enumerá-los. Além disso, os problemas de Análise Combinatória tornam-se um desafio para os alunos, pois exigem flexibilidade de pensamento, concentração, discussão e organização de estratégias para resolvê-los. Ela também serve de base para várias subáreas da Matemática e outras áreas do conhecimento científico, considerando seu vasto campo de aplicações.

Segundo a Base Nacional Comum Curricular, BNCC, uma das habilidades a ser desenvolvida nos alunos do Ensino Médio é "Resolver e elaborar problemas de contagem envolvendo agrupamentos ordenáveis ou não de elementos, por meio dos Princípios Multiplicativo e Aditivo, recorrendo a estratégias diversas, como o diagrama de árvore". (BRASIL, 2018. p. 537)

A Contagem ao mesmo tempo que possibilita uma abordagem mais completa da probabilidade por si só, permite também o desenvolvimento de uma nova forma de pensar em Matemática denominada raciocínio combinatório, presente na BNCC. Esse raciocínio consiste em decidir sobre a forma mais adequada de organizar números ou informações para poder contar os casos possíveis.

O uso das fórmulas para resolver um problema de Análise Combinatória deve ser consequência do raciocínio combinatório desenvolvido e deve ter a função de simplificar os cálculos quando a quantidade de dados for muito grande. Os conteúdos de Análise Combinatória devem ter maior espaço e serem mais trabalhados no Ensino Médio, mantendo de perto a perspectiva da resolução de problemas, para evitar-se a teorização excessiva.

De acordo com Martinho e Ponte (2007), uma das maneiras que os alunos podem evoluir na tarefa de aprender é realizando trabalhos em grupo, aprendendo a discutir com os colegas aquilo que pensaram individualmente. Para ele, depois deste estágio os alunos estão preparados para uma etapa mais complexa que envolve a capacidade de explicar suas 
ideias, argumentar e procurar convencer os colegas das suas opiniões bem como ouvir e contra argumentar.

Observa-se, neste sentido, que a comunicação tem um papel importante, em especial, na sala de aula na interação professor-aluno e aluno-aluno. Nesse aspecto, no que se refere à comunicação, como sendo a capacidade do aluno conseguir explicar sua ideia, efetuando troca de conhecimento, Sarramona (1987) afirma que tal comunicação só ocorre quando o receptor interioriza significativamente a informação. Se o receptor não lhe atribui qualquer significado, apenas se pode falar em transmissão.

Busca-se aporte na teoria de Aprendizagem Significativa a fim de enfatizar a importância de que os alunos aprendam um conteúdo de forma significativa. De acordo com ela existem duas condições para que ocorra aprendizagem significativa: é essencial que o aluno tenha uma disposição para aprender e o material didático utilizado deve ser potencialmente significativo para o aluno.

A fim de analisar possíveis contribuições para a melhoria na aprendizagem de Análise Combinatória, Jacoby (2019) elaborou uma proposta de sequência didática para o ensino de Análise Combinatória pautada em trabalhos em grupo e na comunicação matemática, que foi desenvolvida em uma turma do $2^{\circ}$ Ano do Ensino Médio, de uma escola pública da cidade de Chapecó, SC.

Este artigo apresenta um recorte de algumas destas atividades e tem como objetivo investigar contribuições para a aprendizagem significativa de Análise Combinatória, considerando o trabalho em grupo e a comunicação Matemática. Como objetivos específicos elencam-se: (1) resgatar os conhecimentos prévios dos alunos sobre os princípios fundamentais da contagem; (2) analisar as interações estabelecidas nos grupos e a comunicação matemática para a aprendizagem dos conteúdos trabalhados; (3) desenvolver neles a capacidade de criar estratégias de contagem e organização para a resolução de problemas a fim de desenvolver o pensamento combinatório; (4) elencar possíveis contribuições para a aprendizagem significativa dos conteúdos trabalhados.

Trata-se de uma pequisa de natureza qualitativa e para a análise dos dados coletados consideram-se categorias textuais de análise.

\section{APRENDIZAGEM SIGNIFICATIVA, TRABALHO EM GRUPO E COMUNICAÇÃO MATEMÁTICA}

A fim de fundamentar o trabalho discorre-se sobre a teoria da Aprendizagem Significativa e sobre a importância de se trabalhar em grupo a fim de exercitar a comunicação matemática. 


\section{Aprendizagem Significativa}

De acordo com Ausubel a aprendizagem por recepção significativa é aquela aprendizagem que necessita fazer algum sentido para os alunos e, nesse processo, a informação deverá interagir e ancorar-se nos conceitos já existentes na estrutura cognitiva do aluno, os subsunçores. Para ele,

A aprendizagem por recepção significativa envolve, principalmente, a aquisição de novos significados a partir de material de aprendizagem apresentado. Exige quer um mecanismo de aprendizagem significativa, quer a apresentação de material potencialmente significativo para o aprendiz. Por sua vez, a última condição pressupõe (1) que o próprio material de aprendizagem possa estar relacionado de forma não arbitrária (plausível, sensível e não aleatória) e não literal com qualquer estrutura cognitiva apropriada e relevante (i.e., que possui significado 'lógico') e (2) que a estrutura cognitiva particular do aprendiz contenha ideias ancoradas relevantes, com as quais se possa relacionar o novo material. A interacção entre novos significados potenciais e ideias relevantes na estrutura cognitiva do aprendiz dá origem a significados verdadeiros ou psicológicos. Devido à estrutura cognitiva de cada aprendiz ser única, todos os novos significados adquiridos são, também eles, obrigatoriamente únicos. (AUSUBEL, 2013, p. 1)

Ainda, segundo Moreira,

a aprendizagem significativa é um processo por meio do qual uma nova informação relaciona-se com um aspecto especificamente relevante da estrutura de conhecimento do indivíduo, ou seja, este processo envolve a interação da nova informação com uma estrutura de conhecimento específica, a qual Ausubel define como conceito subsunçor, ou simplesmente subsunçor, existente na estrutura cognitiva do indivíduo. (MOREIRA, 2011 p. 153)

Observa-se que o conhecimento prévio que o aluno dispõe, sobre determinado assunto, é a variável isolada mais importante e que mais influencia na aprendizagem significativa de novos conteúdos, porém nem sempre ela é uma variável facilitadora dessa aprendizagem. Em alguns casos é necessário utilizar recursos instrucionais chamados de organizadores prévios a fim de suprir deficiências de subsunçores ou para mostrar a relação entre novos conhecimentos e os subsunçores já existentes. Conforme Moreira (2011) esses organizadores prévios podem ser expositivos, que é quando o material didático não é familiar e o aprendiz não tem subsunçores ou comparativos que é quando o novo material é relativamente familiar.

De acordo com Moreira (2011) e, Masini e Moreira (2017), existem estratégias e instrumentos (didáticos) facilitadores da aprendizagem significativa, com destaque para as atividades colaborativas presenciais e as sequências de ensino e aprendizagem. Ainda, conforme Masini e Moreira (2017, p. 43) "as atividades colaborativas presenciais são aquelas em que uma tarefa, uma situação-problema deve ser realizada colaborativamente em pequenos grupos [...] em sala de aula com a mediação do professor" e as sequências de ensino e aprendizagem são "sequências de atividades de ensino planejadas, organizadas passo-a-passo, visando facilitar, promover, a aprendizagem de um certo conhecimento, 
tópico, conteúdo."

Observa-se que essas estratégias e/ou instrumentos (didáticos) têm grande potencial para facilitar a aprendizagem significativa uma vez que viabilizam o intercâmbio, a negociação de significados e, colocam o professor na posição de mediador do processo.

Um outro ponto de destaque é como fazer a avaliação da aprendizagem significativa. Conforme destaca Moreira (2011, p. 51), para a avaliação, Ausubel propõe que "a melhor maneira de evitar a simulação da aprendizagem significativa é propor ao aprendiz uma situação nova, não familiar, que requeira máxima transformação do conhecimento adquirido". Porém, como a avaliação da aprendizagem significativa deve ser formativa e recursiva, Moreira (2011, p. 52) enfatiza que “é necessário buscar evidências de aprendizagem significativa ao invés de querer determinar se ocorreu ou não". Nesse sentido é importante que o aluno refaça as atividades mais de uma vez se necessário, justifique suas respostas até elas fazerem sentido para ele.

\section{Trabalho em Grupo e Comunicação Matemática}

Comunicação é um processo que envolve a transmissão e a recepção de mensagens entre uma fonte emissora e um destinatário receptor, cujas informações podem ser transmitidas por intermédio de recursos físicos ou de aparelhos e dispositivos técnicos.

Conforme Bordenave (2007), a comunicação serve para que as pessoas se relacionem entre si, transformando-se mutuamente e a realidade que as rodeia. Pela comunicação as pessoas compartilham experiências, ideias e sentimentos. Ao se relacionarem como seres interdependentes, influenciam-se mutuamente e, juntos, modificam a realidade onde estão inseridas.

Em relação ao aluno, Martinho e Ponte (2017) enfatizam que o mesmo leva para a sala de aula vivências anteriores e a partir delas espera-se que ele "aprenda e cresça cognitiva, afetiva e socialmente através das experiências que a escola lhe proporciona. Isto envolve um longo processo comunicativo. Enquanto agente nesse processo, o aluno pode ser tomado individualmente ou no contexto mais geral do grupo de trabalho ou da turma." (MARTINHO e PONTE, 2007, p. 17).

Sobre o trabalho em grupo, conforme Cohen e Lotan (2017, p. 1) ele é definido no ambiente escolar como "alunos trabalhando juntos em grupos pequenos de modo que todos possam participar com tarefas claramente atribuídas”. E mais, os alunos devem realizar essas tarefas sem a supervisão direta e imediata do professor. Nos grupos, o professor tem o papel de mediador estabelecendo conexões entre os participantes e incentivando a interação entre eles. 
Ainda de acordo com Cohen e Lotan (2017, p. 7), o trabalho em grupo tem um potencial grande para atingir alguns objetivos de aprendizagem intelectual e social. Ele tem potencial para a aprendizagem conceitual, para a resolução de problemas e para a melhoria da proficiência acadêmica; para a melhoria das relações intergrupais; o desenvolvimento de habilidades para trabalhar em equipe; manter o máximo possível de alunos de uma turma envolvidos em uma atividade; tornar mais acessíveis a um número maior de alunos da turma tarefas de aprendizagem.

Todavia cabe ao professor, em sala de aula, proporcionar um ambiente que se assemelhe ao nível de comunicação instrutivo e estabelecer um cenário em que o aluno tem a responsabilidade de expor as suas ideias e efetuar explicações ao longo das aulas. A presença do professor em sala de aula, quando os alunos estão em grupos dedicados a realização de tarefas, deve ser discreta. Não compete a ele dar respostas prontas aos integrantes dos grupos, e sim questioná-los e desafiá-los, a interagirem entre si nos grupos, pois no momento que os alunos efetuam essa "troca" de conhecimento, vão clareando o significado das palavras e combinando seu conhecimento com o conhecimento de seus colegas.

A partir destas afirmações, a fim de encontrar evidências de aprendizagem significativa de conteúdos de Análise Combinatória são trabalhadas situações-problema, com atividades em pequenos grupos, considerando também a comunicação matemática.

\section{METODOLOGIA DA PESQUISA}

A presente pesquisa pode ser classificada como qualitativa do tipo estudo de caso em que participaram dela os 28 alunos matriculados em uma turma do $2^{\circ}$ Ano do Ensino Médio de uma escola pública da cidade de Chapecó, SC, em 2019.1.

A coleta dos dados da pesquisa foi realizada pela primeira autora, professora regente da turma na época, no horário das aulas de Matemática, considerando que a Análise Combinatória integra o currículo da disciplina de Matemática do $2^{\circ}$ Ano do Ensino Médio.

A pesquisa foi desenvolvida em 10 encontros sendo que nesses encontros os alunos desenvolveram atividades individuais e/ou em grupos de 2 até 6 pessoas, que se mantiveram os mesmos durante a realização das atividades.

A coleta de dados ocorreu por meio de observações, registros em diário de bordo e fotos, bem como os materiais escritos pelos alunos, teste inicial e final, e também pelo questionário aplicado no término do trabalho. Os diálogos que constam no artigo foram escritos a partir das anotações e observações. E a análise dos dados desta pesquisa ocorreu de forma textual discursiva, a partir da proposição de três categorias de análise. 


\section{ATIVIDADES DESENVOLVIDAS}

Nesta seção apresentam-se algumas das atividades desenvolvidas pelos alunos.

\section{(A) Primeiro encontro: aplicação do jogo Mastermind}

Inicialmente os alunos foram divididos em dupla e iniciaram jogando o nível I do jogo de estratégia Mastermind ${ }^{l}$, sendo que cada dupla jogou apenas duas vezes, pois acharam o jogo muito fácil. Na sequência jogaram o nível II, com um nível mais elevado de dificuldade. As figuras 1 (a) e (b) apresentam a solução do jogo encontrada, respectivamente, pela Dupla 2 e Dupla 3.

Na Figura 1 (a), a senha criada pelo desafiador era: verde, roxo, amarelo e laranja e, apesar de todas as estratégias utilizadas em nenhuma das dez jogadas realizadas o desafiado conseguiu acertar as quatro cores da senha, para que pudesse reorganizá-las, tornando o jogo mais fácil.

Na Figura 1 (b), a senha proposta pelo desafiador era: azul, vermelha, roxa e laranja, nessa ordem. Na quinta jogada o desafiado acertou as cores das peças da senha e, em mais duas jogadas colocou-as na ordem correta acertando senha proposta.

Figura 1: Jogo Mastermind concluído sem sucesso (a) e com sucesso (b).
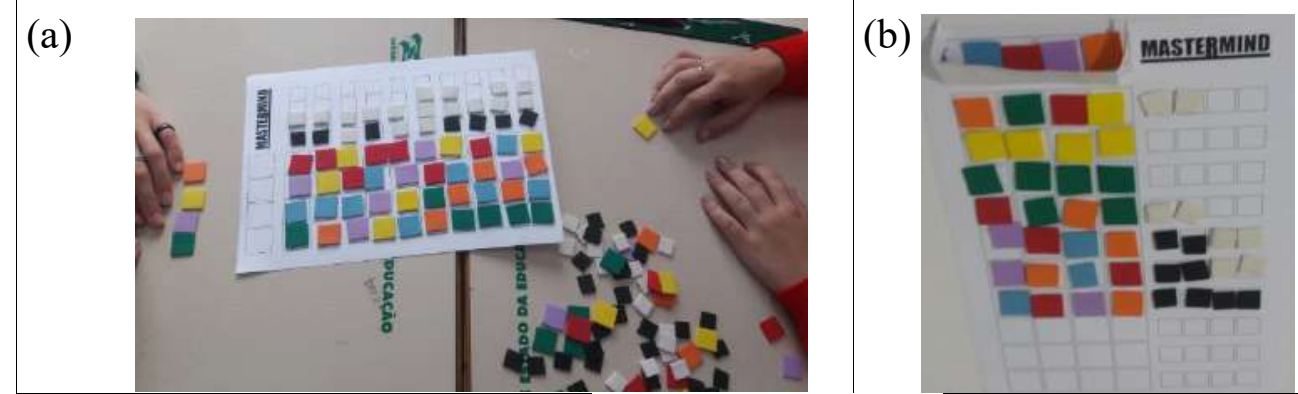

Fonte: As Autoras, 2019.

Esta atividade foi desenvolvida com o objetivo de motivar os alunos para o estudo da Análise Combinatória, bem como trabalhar de modo intuitivo o princípio Multiplicativo. Este jogo foi retomado no quinto encontro com o objetivo de mostrar aos alunos como calcular o número total de sequências possíveis de senhas, formadas por quatro cores distintas.

\section{(B) O Teste Diagnóstico}

No segundo encontro os 23 alunos presentes na aula realizaram, individualmente, o teste diagnóstico, composto por 4 questões abordando os conteúdos: princípios da contagem, arranjo simples e combinação simples. Porém, observou-se que não houve muita

\footnotetext{
${ }^{1} \mathrm{O}$ jogo de Mastermind é um jogo de estratégia em que um jogador (o desafiado) tem que adivinhar uma senha proposta por outro jogador (o desafiador). O jogo e suas regras podem ser encontrados em Jacoby (2019). Uma versão original encontra-se disponível em: http://www.clickjogos.com.br/Jogosonline/Puzzle/Mastermind
} 
dedicação deles na sua realização, uma vez que muitos alunos deixaram questões sem resposta.

A primeira questão foi resolvida por todos e aproximadamente $70 \%$ deles acertaram-na. A Figura 2 ilustra a estratégia que foi mais utilizada pelos alunos para resolvê-la: apenas multiplicaram a quantidade de modelos pela quantidade de cores, chegando ao resultado correto.

Figura 2: Resolução da Questão 1 realizada pelo aluno de codinome Busatinho.

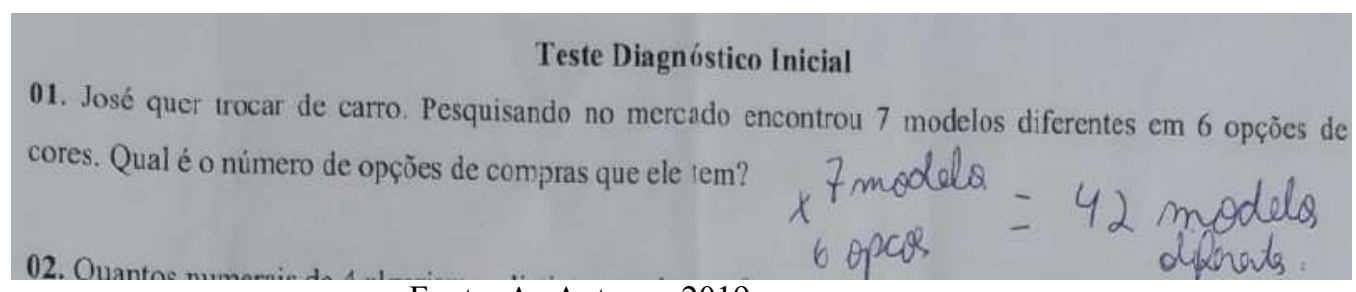

Fonte: As Autoras, 2019

Em relação a segunda questão, apenas um aluno não a resolveu. Dos 22 alunos que resolveram-na, 23\% resolveram-na corretamente. A Figura 3 ilustra a solução dada pela aluna de codinome Marina, semelhante a solução realizada pelos demais que acertaram-na. Sua estratégia foi listar todas as possibilidades inclusive o zero, na primeira posição, utilizando um movimento cíclico, sistemático e completo; em seguida anulou todos os números iniciados em zero, pois não configuram números de quatro algarismos.

Figura 3: Resolução da Questão 2 apresentada pela aluna de codinome Marina.

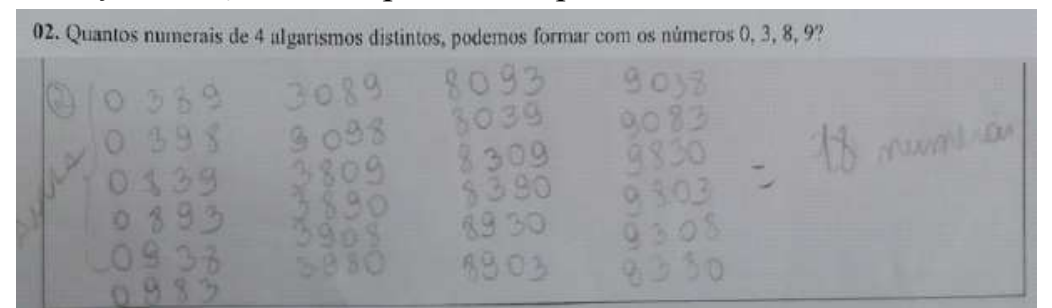

Fonte: As Autoras, 2019.

Nenhum aluno acertou as questões 3 e 4, sendo que a maioria deles deixou-as sem solução e os que responderam, não as acertaram. Isso pode ter acontecido por elas serem mais complexas.

Na Figura 4 apresenta-se uma estratégia interessante de solução da Questão 4, porém errada. O aluno observou, de forma equivocada, que em cada ponto fixado são formados 4 triângulos, como são 6 pontos, obteve 24 triângulos. Porém, o aluno não se atentou ao fato de que procedendo dessa forma, alguns dos triângulos se repetiriam, obtendo deste modo o mesmo triângulo. 
Figura 4: Resolução da Questão 4 apresentada pelo aluno de codinome Brinco Preto.

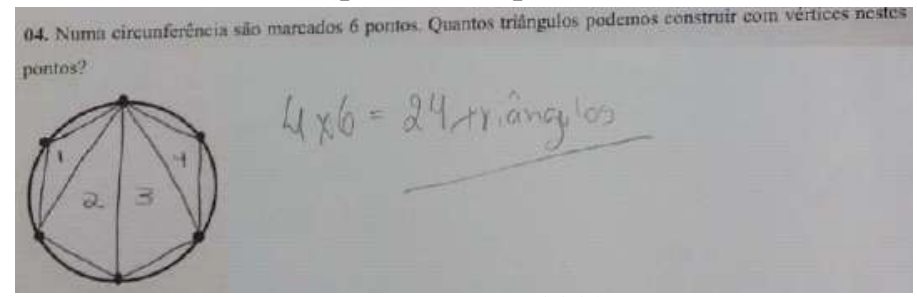

Fonte: As Autoras, 2019.

A partir da análise deste teste verificou-se que os alunos são capazes de resolver problemas simples de contagem, mesmo eles não tendo estudado esse conteúdo ainda. Credita-se a isso o fato deles possuírem algum conhecimento prévio sobre os princípios Aditivo e Multiplicativo estudados em anos anteriores. Porém, quando submetidos a situações-problema com um nível maior de complexidade não conseguiram organizar-se para resolver essas situações.

Nesse sentido, foram levadas nas aulas seguintes mais situações-problema, aqui denominados desafios, para que eles pudessem resolvê-las não mais individualmente, mas sim em pequenos grupos a fim de suprir deficiências de subsunçores bem como incentivar a resolução desse tipo de problema. Esses desafios são entendidos como organizadores prévios comparativos.

\section{(C) Algumas das Atividades Desenvolvidas no Terceiro e no Quarto Encontros}

No encontro seguinte foi apresentado à turma, o conceito de numeral, a partir de exposição oral e dialogada. Na sequência foi apresentado um exercício, no qual destaca-se que houve bastante interação da turma na sua resolução, conforme parte de diálogos ocorridos e descritos no Quadro 1.

Quadro 1: Diálogo da Professora com a Turma.

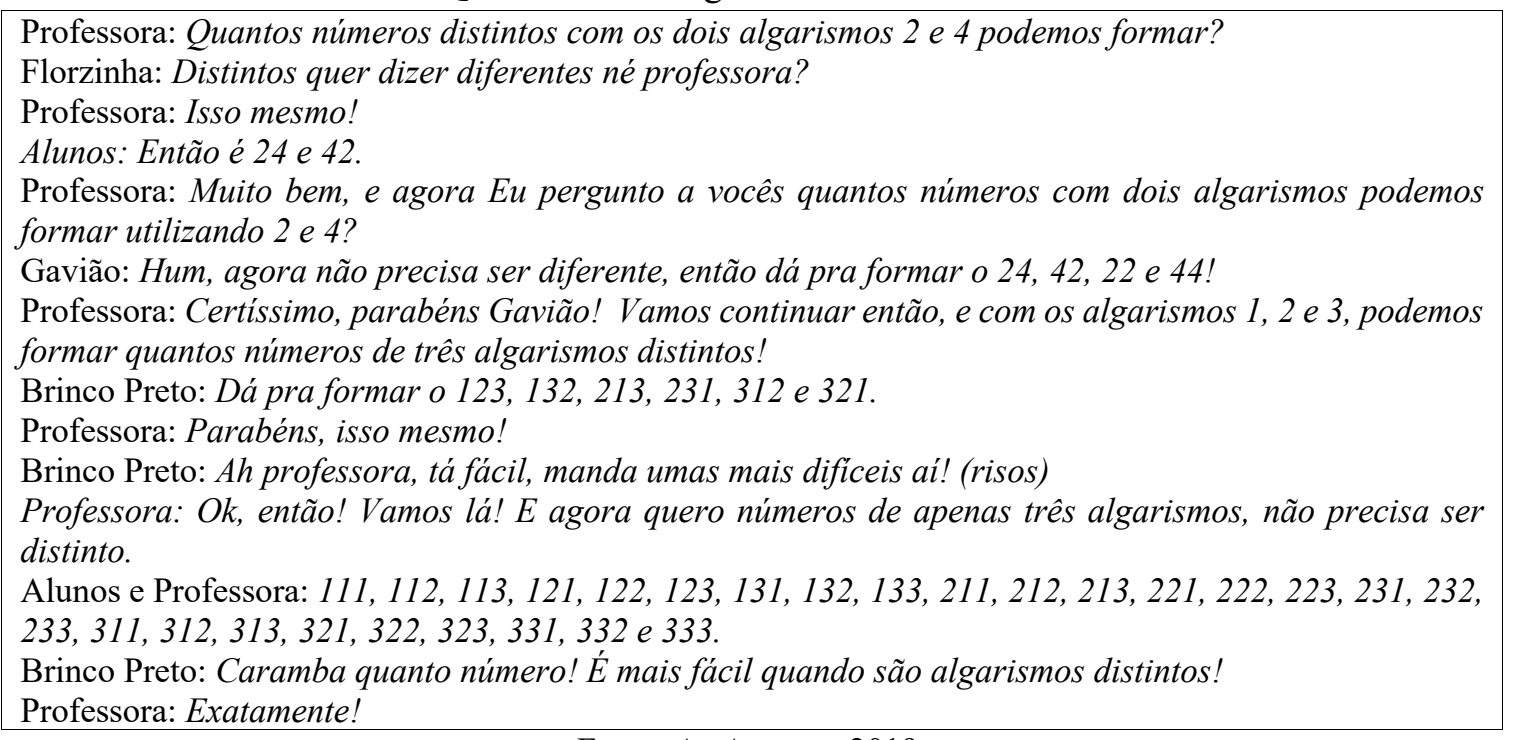
Fonte: As Autoras, 2019.

No decorrer dessa aula os alunos foram demonstrando maior segurança para responder as questões individualmente e em grupo, tornando os diálogos mais produtivos. 
Percebeu-se que eles haviam compreendido o conceito de numeral.

No que se refere à comunicação matemática, foi possível observar avanços, pois os alunos já não eram apenas receptores de informações. No decorrer dos diálogos eles queriam expressar suas ideias, sendo uma oportunidade para valorizar a capacidade individual deles.

Apresentam-se na sequência quatro situações-problema de contagem, denominados Desafio 1, Desafio 2, Desafio 4 e Desafio 5, resolvidos pelos alunos, em grupo.

Desafio 1: Uma lanchonete vende uma promoção de lanche a um preço único. No lanche, estão incluídos um sanduíche, uma bebida e uma sobremesa. São oferecidas três opções de sanduíches: hambúrguer especial, sanduíche vegetariano e cachorro-quente completo. Como opção de bebida pode-se escolher entre 2 tipos: suco de maçã ou guaraná. Para a sobremesa, existem quatro opções: cupcake de cereja, cupcake de chocolate, cupcake de morango e cupcake de baunilha. Considerando todas as opções oferecidas, de quantas maneiras um cliente pode escolher o seu lanche?

Todos os grupos responderam corretamente esse desafio. Houve o envolvimento de praticamente todos os integrantes dos grupos nessa atividade, mesmo daqueles alunos que não participavam muito das aulas.

Desafio 2: Quatro clubes de futebol estão disputando um campeonato: Predadores, Touros a Solta, Canibais e Dois Pés Esquerdos. Qual é o número de resultados possíveis para os três primeiros lugares?

Apenas metade dos grupos resolveu esse desafio. Alguns alunos tiveram dificuldade em entendê-lo, conforme diálogos realizados em um grupo (Quadro 2).

Quadro 2: Diálogos em um Grupo.

Florzinha: Mas como assim tem quatro times e só tem três lugares? Não tô entendendo!

Gavião: Mas isso não tem nada a ver, podia ter 20 times e só três lugares, porque o que a pergunta tá pedindo é como poderia fica essas três primeiras posições!

Florzinha: Ai Meu Deus do Céu, já não tô entendendo mais nada!

Gavião: Assim, poderia dá Predadores em primeiro, Touros em segundo e Canibais em terceiro né?

Florzinha: Sim.

Gavião: Então, significa que Dois pés esquerdos não vai ganhar nada, um sempre vai ficar de fora, entendeu agora?

Florzinha: Hum, acho que agora entendi... tá vamos ver as outras opções pra ver quanto que dá.

Fonte: As Autoras, 2019.

A Figura 5 apresenta a solução realizada pelo Grupo 1, sendo que os alunos apenas efetuaram o produto da quantidade de times pelas posições, chegando ao resultado correto.

Figura 5: Resolução do Desafio 2 realizada pelo Grupo 1.

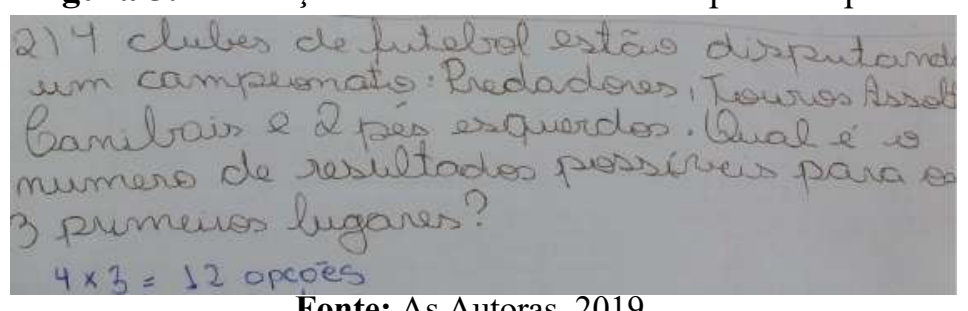

Fonte: As Autoras, 2019. 
Outras duas resoluções corretas do Desafio 2 estão nas figuras 6 (a) e (b), sendo que a primeira (a) consistiu em determinar todas as opções estando um dos times em primeiro lugar, na sequência tomar como verdade para os demais e apenas multiplicar; já na segunda solução (b) o grupo utilizou o princípio Multiplicativo, observando que para o primeiro lugar existem quatro possibilidades de times, para o segundo três e para o terceiro lugar duas possibilidades de times.

Figura 6: Resolução do Desafio 2 realizado pelos grupos 3 (a) e 5 (b).

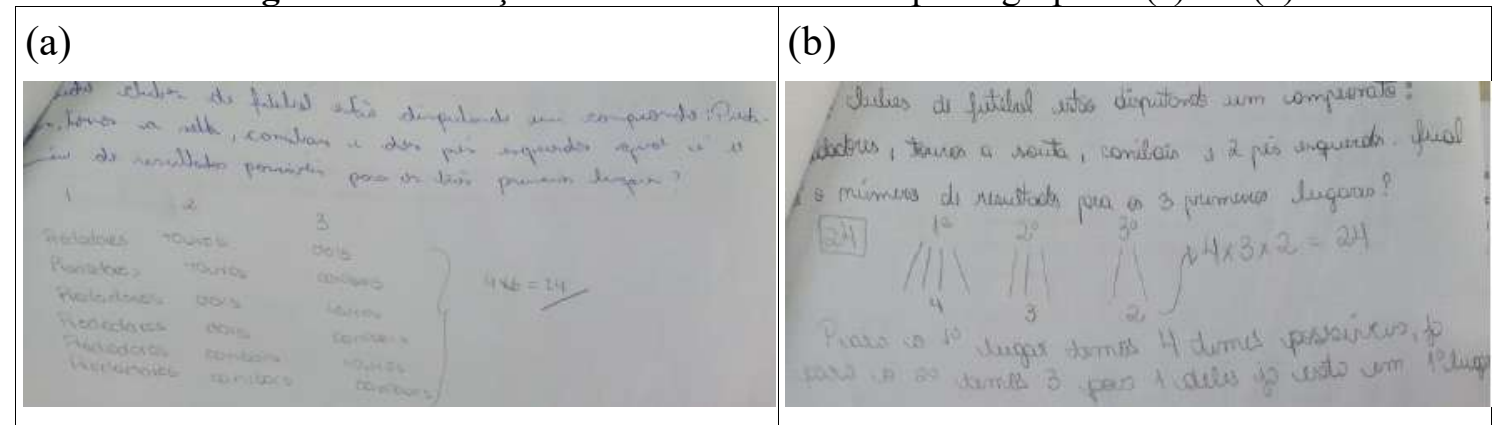

Fonte: As Autoras, 2019.

Desafio 4: Qual a quantidade de uniformes diferentes que podem ser formados pelas opções fornecidas por um patrocinador: cinco camisas (azul, vermelha, amarela, roxa e verde), três de calção (preto, branco e cinza) e duas opções de meiões (azul e preta)?

Nesse desafio os grupos já estavam familiarizados sobre como deveriam proceder para resolvê-lo. Notaram que a maneira de resolvê-lo era semelhante ao Desafio 1. Apenas um grupo não chegou ao resultado correto.

Desafio 5: Dois pés esquerdo já está no campeonato estadual junto com outros 11 times. De acordo com o regulamento na primeira fase todos os times devem se enfrentar. Determine quantos jogos serão a todo nessa primeira fase. Elabore um esquema e apresente o calendário esportivo.

A resolução desse desafio gerou bastante discussões nos grupos, pois não chegavam a uma solução em que todos concordassem. Cada um pensava de forma diferente. Dos seis grupos, dois não conseguiram obter a resposta correta.

As figuras 7 (a) e (b) ilustram a resolução realizada pelos grupos 2 e 3, respectivamente, sendo que na resolução do Grupo 2 não foi considerada a hipótese de que “Os times enfrentavam-se uma única vez”. Portanto, na solução obtiveram o dobro de possibilidades; já na resolução do Grupo 3 (b), eles consideraram essa hipótese e resolveram o desafio corretamente. Essa estratégia também foi utilizada pelos demais grupos que acertaram a questão. 
Figura 7: Resolução do Desafio 5 realizada pelos grupos 2 (a) e 3 (b).

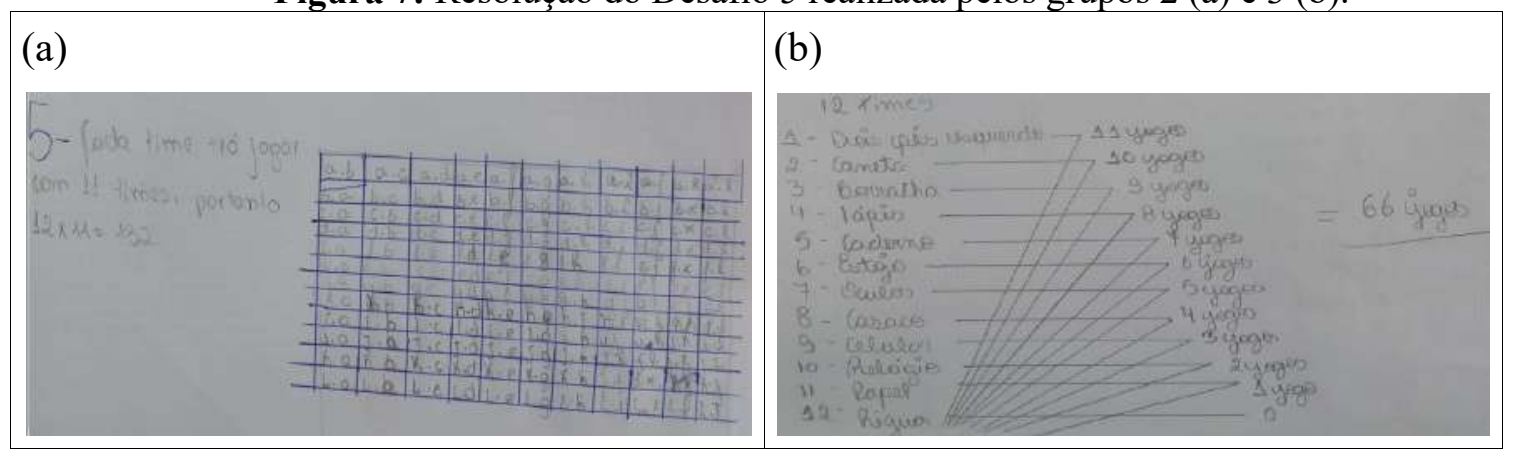

Fonte: As Autoras, 2019.

$\mathrm{Na}$ discussão com os alunos sobre a dinâmica da aula, eles defenderam a realização de mais atividades em grupo, afirmaram que gostaram de debater suas ideias com os colegas, que se sentiram mais seguros em poder dividir com o outro a responsabilidade de resolver um problema e que ficava mais fácil entender o enunciado de um problema quando ele era discutido em grupo.

Observa-se que os alunos conseguiram resolver problemas sobre contagem. Uma possibilidade para isso é que eles tenham utilizado conhecimentos prévios sobre os princípios fundamentais da contagem adquiridos ao longo da trajetória escolar, bem como as discussões realizadas nos grupos fazendo-os retomarem conceitos "esquecidos".

\section{(D) Observações em Relação as Atividades Desenvolvidas do Quinto ao Nono Encontros}

Após a resolução dos desafios, nestes encontros foram trabalhados, de modo tradicional, com aulas expositivas e dialogadas, os conteúdos de Análise Combinatória (Fatorial, Princípio Aditivo e Multiplicativo, Arranjo Simples, Permutação Simples e com Repetição e Combinação Simples), conceitos, propriedades e fórmulas. Novamente, os exercícios e as situações-problema foram resolvidos pelos alunos em grupo, mantendo-se os grupos já formados.

Durante a explanação dos princípios Aditivo e Princípio Multiplicativo foi possível constatar que houve compreensão dos conceitos, pois alguns alunos observaram que já haviam utilizado eles na resolução de desafios, como mostra o diálogo apresentado no Quadro 3. 
Quadro 3: Diálogos da Professora com a Turma.

Professora: Então turma, conseguiram compreender a diferença entre Princípio Aditivo e Multiplicativo? Alunos: Sim!

Professora: Alguém poderia me dar um exemplo em que utilizamos o princípio multiplicativo diferente dos citados acima?

Marina: Nos desafios que fizemos tinha várias, tipo aquela que falava dos lanches, a gente pegou e multiplicou todas as opções que nós tínhamos.

Professora: Isso mesmo, esse é outro exemplo do uso do princípio Multiplicativo. E alguém poderia me dizer se em algum dos desafios que fizemos utilizamos o Princípio Aditivo?

(Alguns segundos de silêncio)

Professora: Então, ninguém se arrisca? Brinco Preto?

Brinco Preto: Eu acredito que seja o desafio que pedia pra gente calcular o número de jogos de um campeonato que fizemos $11+10+9$.. e assim por diante.

Professora: Exatamente, para poder resolver esse desafio vocês utilizaram o Princípio Aditivo.

Fonte: As Autoras, 2019.

Observa-se também a evolução deles na comunicação matemática, pois já haviam adquirido alguns conhecimentos oportunizando um diálogo mais consistente sobre esses conteúdos.

Em relação aos conteúdos de Análise Combinatória destaca-se, de modo geral, que durante as explanações, pela professora, os alunos não apresentaram dúvidas. Elas surgiram na resolução de exercícios e/ou situações-problema e, na maioria das vezes, versavam sobre a interpretação do enunciado. Quando isso acontecia recorriam à professora para auxiliálos nessa interpretação.

Uma outra dúvida que surgiu ao longo desses encontros, na medida que foram introduzidos os conteúdos de arranjo e permutação, foi em relação a qual fórmula deveriam utilizar para resolver o exercício. A professora explicou que muitos exercícios de Análise Combinatória podem ser resolvidos sem precisar usar uma fórmula. Os mesmos podem ser resolvidos utilizando-se os princípios Aditivo e Multiplicativo e que a fórmula, algumas vezes, simplifica o cálculo. Novamente, observa-se que a dificuldade está na interpretação do enunciado do exercício aliada a estratégia de solução, dificuldade bastante comum quando se trabalha com Análise Combinatória.

No nono encontro os alunos resolveram uma lista de exercícios abrangendo todos os agrupamentos estudados. Inicialmente eles mostraram insegurança para resolver as atividades, antes de iniciar uma questão chamavam a professora para verificar se estavam procedendo de maneira correta, ou seja, se a fórmula escolhida estava correta. No decorrer da aula, depois de resolverem alguns exercícios, essa insegurança foi passando.

Ao final do nono encontro foi aplicado o questionário de avaliação do trabalho desenvolvido, Quadro 5, seção Análise dos Resultados.

\section{(E) Algumas Observações em Relação as Atividades Desenvolvidas no Décimo Encontro}

No último encontro foi aplicado o teste final, individualmente, para os 28 alunos 
participantes da pesquisa, composto por 10 questões dissertativas de Análise Combinatória. Essas questões assemelhavam-se aos desafios já trabalhados em grupo, no início da pesquisa.

Apresentam-se algumas das soluções realizadas pelos alunos das Questões 1, 3 e 4, desse teste. O texto completo encontra-se disponível em Jacoby (2019).

Questão 1: Quantos resultados possíveis diferentes pode haver numa corrida com 6 atletas em que serão outorgadas 1 medalha de ouro, 1 de prata e 1 de bronze?

Essa questão foi resolvida pelos 28 alunos, sendo que 20 resolveram-na corretamente e os que não a resolveram corretamente, não o fizeram porque utilizaram fórmulas erradas. As estratégias corretas de solução utilizaram a fórmula de arranjo (Figura 8 (a)) ou o princípio Multiplicativo (Figura 8 (b)).

Figura 8: Resolução da Questão 1 pela aluna de codinome (a) Lindinha e (b) Estrelinha do Mar. (a)

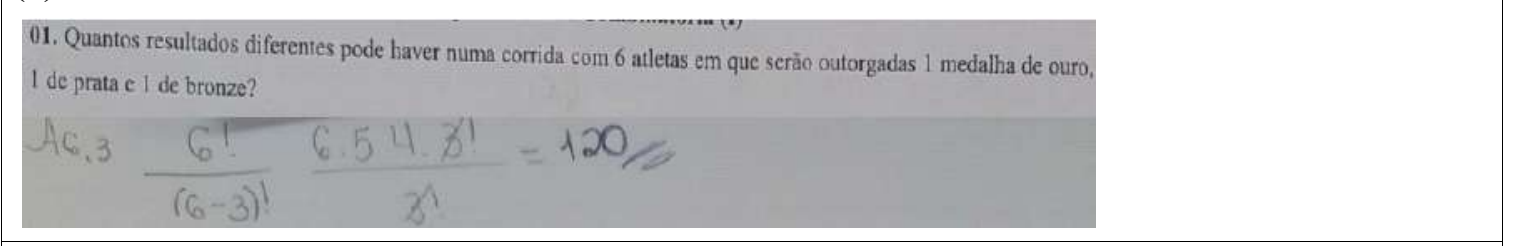

(b)

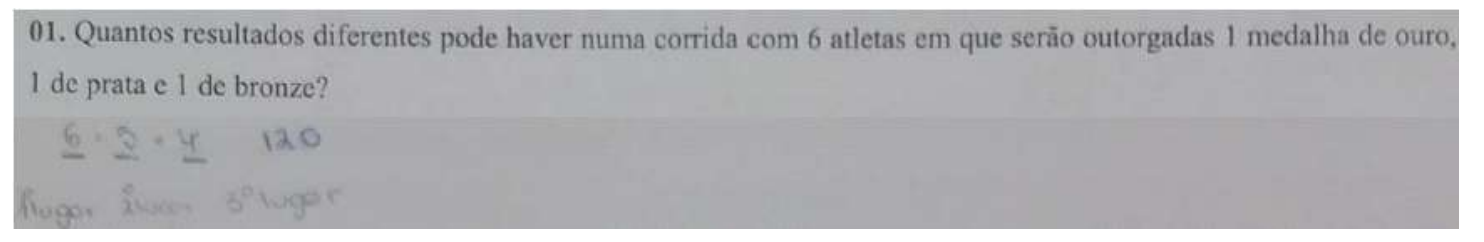

Fonte: As Autoras, 2019.

A terceira questão do teste de final era semelhante a segunda questão do teste diagnóstico.

Questão 2 (Teste Diagnóstico): Quantos numerais de 4 algarismos distintos podemos formar com os números $0,3,8,9$ ?

Questão 3 (Teste Final): Usando os algarismos 1, 3, 4, 6 e 9, quantos números de 3 algarismos distintos podemos formar?

A Questão 2 (Teste Diagnóstico) foi resolvida corretamente por apenas 23\% dos alunos, já a Questão 3 (Teste Final) 64\% deles resolveram-na corretamente, o que equivale a 18 alunos.

A Figura 3 apresenta a solução realizada pela aluna de codinome Marina. Ela descreveu todas as possibilidades, pois não tinha o conhecimento de fórmulas, já na sua solução apresentada na Figura 9 percebe-se que aplicou corretamente a fórmula. 
Figura 9: Resolução da Questão 3 (Teste Final) pela aluna de codinome Marina.

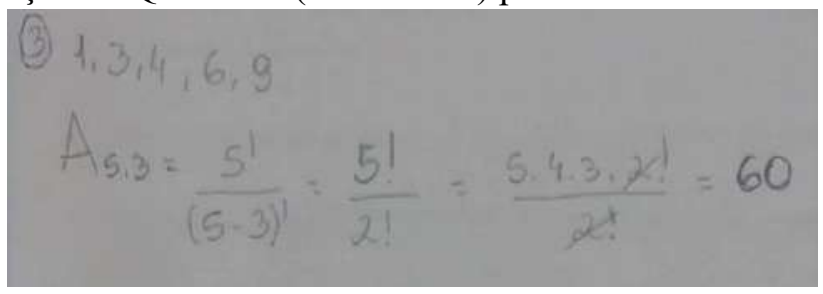

Fonte: As Autoras, 2019.

A Questão 4 do teste final teve o menor índice de acertos. Apenas 2 alunas resolveram-na corretamente, sendo que ambas aplicaram a fórmula para calcular o número total de combinações possíveis. Uma das soluções é dada pela Figura 10.

Figura 10: Resolução da Questão 4 realizada pela aluna de codinome Girassol.

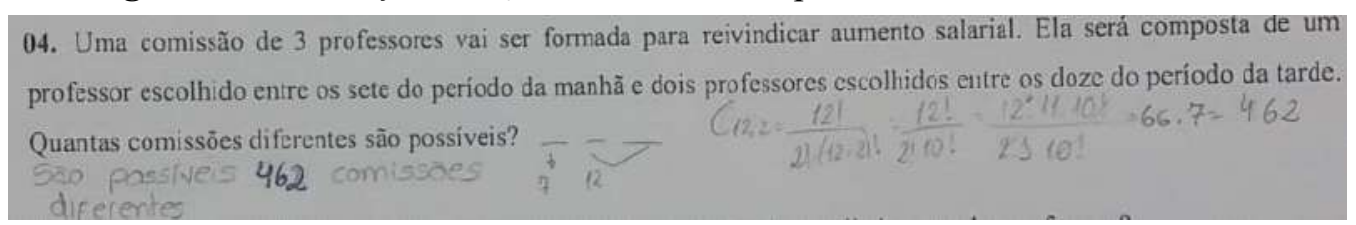

Fonte: As Autoras, 2019.

Atribui-se o baixo índice de acertos da questão à interpretação incorreta do enunciado. Muitos alunos efetuaram uma combinação de 19 professores tomados 3 a 3, ignorando o fato de haver restrições para os turnos de trabalho.

Nas soluções apresentadas pelos alunos nas questões do teste final percebe-se que eles optaram por utilizar as fórmulas em questões que apresentavam um número maior de elementos, quando listadas todas as possibilidades. Porém, nas questões em que era possível descrever todas as possibilidades, em um número menor de passos, elas foram resolvidas utilizando-se os princípios fundamentais da contagem, dando mais segurança em relação a veracidade da resposta. Alguns alunos utilizaram os dois métodos de resolução, a fim de validar os resultados obtidos.

No teste diagnóstico, poucos alunos justificaram as respostas dos exercícios ou problemas. Já no teste final houve um avanço significativo na construção de argumentos mais consistentes, as respostas dadas provinham de proposições apresentadas de forma clara e organizada.

\section{ANÁLISE DOS RESULTADOS}

Antes da análise dos resultados apresenta-se o Quadro 4. 
Quadro 4: Resultado do Questionário de Avaliação ${ }^{2}$

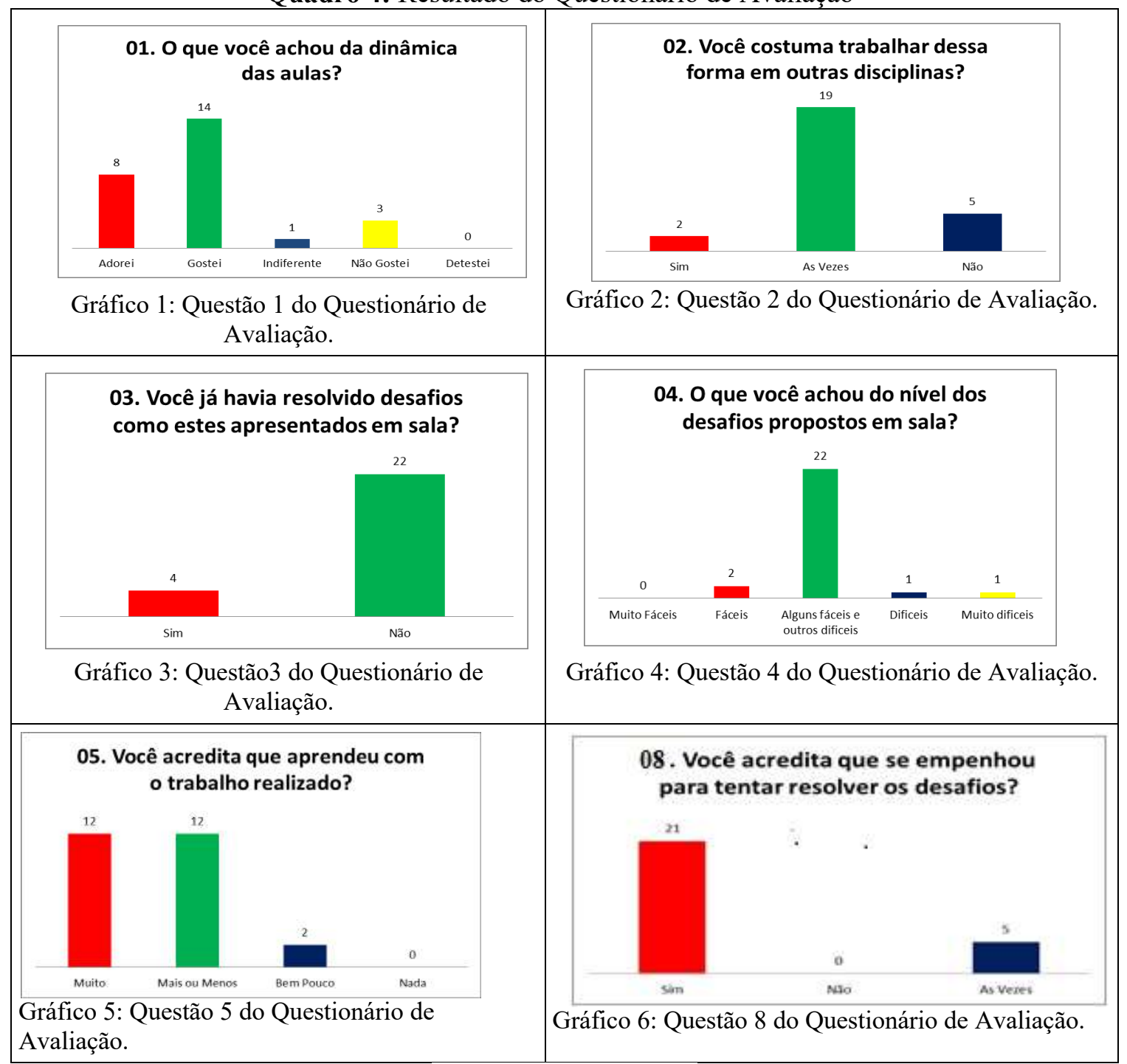

Fonte: As Autoras, 2019

Para a análise dos dados são consideradas as seguintes categorias: (i) o envolvimento dos alunos no trabalho em grupo e a comunicação matemática; (ii) aspectos positivos e dificuldades relacionadas ao desenvolvimento da pesquisa; (iii) aspectos que evidenciam contribuições para a aprendizagem significativa de Análise Combinatória.

\section{(i) O envolvimento dos alunos no trabalho em grupo e a comunicação matemática}

As atividades de Matemática desenvolvidas em grupo pelos alunos compreenderam três momentos: o jogo Mastermind, a resolução de problemas denominados desafios, resolvidos utilizando-se apenas os princípios Aditivo e Multiplicativo e em um terceiro momento, a partir da apresentação, pela professora, dos conteúdos de Análise Combinatória e suas fórmulas, foram resolvidos exercícios e situações-problema em que era permitido o uso de fórmulas.

Foi possível observar bastante envolvimento dos alunos nos grupos. Alunos que

\footnotetext{
${ }^{2}$ As Questões 6 e 9 do referido questionário são dissertativas. Alem disso, alguns alunos escreveram comentários nas questões objetivas do referido questionário.
} 
não interagiam muito nas aulas de Matemática mostraram-se interessados, participativos e colaborativos para a solução das atividades. E, conforme descrito no questionário de Avaliação, a maioria dos alunos, gostou de resolver os desafios matemáticos em grupo. Foram muitos comentários elogiando essa metodologia, tais como: "Achei algo bem legal e impulsionou a turma a fazer atividades"; "Foi bom discutir sobre os problemas com os colegas que tem opinião diferente da sua”; "Como comecei já no meio da dinâmica, gostei muito, porque são poucos professores que fazem isso e isso é o diferencial”. Outros alunos inclusive pediram mais aulas nesse formato "Porque aprendi bem melhor com essa dinâmica diferente em grupo, gostaria de mais!".

Outro aspecto relevante é o desenvolvimento da habilidade de trabalhar em equipe, trabalho colaborativo. Observando o registro de diálogos ocorridos nos grupos, verifica-se que no início apenas alguns alunos tinham iniciativa de exporem suas ideias, e no decorrer do processo houve um avanço, pois todos se envolviam nas discussões. Aliado a esse fato pode-se também observar a melhoria no processo de comunicação matemática, na sala de aula, um processo social onde os participantes interagem trocando informações e influenciando-se mutuamente, pois na busca pelo convencimento do outro, os alunos negociaram significados e construíram o próprio conhecimento.

Resolver atividades em grupo exercendo a comunicação matemática oral ou escrita traz benefícios, conforme Queiroz (2015) que afirma que muitas vezes os alunos aprendem com maior facilidade quando um colega está explicando, pois utilizam uma linguagem mais coloquial.

\section{(ii) Aspectos positivos e dificuldades relacionadas ao desenvolvimento da pesquisa}

Conforme já relatado e reforçado pelos alunos nas respostas dadas, Gráfico 4 Quadro 4, algumas dificuldades apresentadas, por eles, foram em relação a resolução dos desafios propostos, em que 22 alunos acharam alguns desafios fáceis e outros difíceis. A única aluna que assinalou que eram todos difíceis comentou: "Difíceis pois existia muita lógica e sem qualquer fórmula é complicado resolver". Entende-se pois nesse momento eles resolveram os problemas propostos utilizando apenas seus conhecimentos prévios sobre os princípios aditivo e multiplicativo.

Outra dificuldade observada está relacionada à resolução de exercícios complementares sobre arranjo, permutação e combinação, após terem sido trabalhados esses agrupamentos. Nesse momento eles deveriam identificar o tipo de agrupamento e resolver a questão, por meio de aplicação ou não de fórmula. Uma parte considerável dos alunos não conseguia diferenciar o tipo do agrupamento presente no exercício, solicitando ajuda da professora para a interpretação do seu enunciado. 
Em relação ao trabalho em grupo e a resolução de desafios, as Questões 2 e 3 do questionário de avaliação, fazem uma enquete sobre se esta estratégia de ensino tem sido trabalhada em outras disciplinas. Como resposta à Questão 2, Gráfico 2 - Quadro 4, a maioria dos alunos respondeu que às vezes em outras disciplinas, em algumas aulas, formam-se grupos para realizar tarefas. No Gráfico 3 - Quadro 4, 22 alunos afirmam que nunca resolveram desafios como os propostos neste trabalho.

Conclui-se que isso se deve ao fato de que normalmente as aulas seguem um estilo tradicional, sendo comum, primeiramente, apresentar o conteúdo, conceitos e propriedades, para só depois resolver as atividades/exercícios.

$\mathrm{Na}$ Questão 1 do referido questionário foi perguntado aos alunos sobre a dinâmica das aulas. Conforme respostas dadas por eles, Gráfico 1 - Quadro 4, observou-se que a maioria deles, quase $80 \%$, gostou ou adorou essa dinâmica.

Pode-se concluir que apesar de algumas dificuldades apontadas em relação ao desenvolvimento da pesquisa, os aspectos referentes a metodologia, a dinâmica das aulas e as estratégias de ensino adotadas foram avaliadas como positivas.

(iii) Aspectos que evidenciam contribuições para a aprendizagem significativa de Análise Combinatória

Em relação a esse aspecto apresentam-se algumas respostas dos alunos, sendo que deles que assinalou que os desafios realizados eram fáceis, argumentou: "Pensávamos que era dificil, mas depois pegamos o ritmo e tiramos de letra". Esse aluno fazia parte de um grupo que conseguiu resolver corretamente todos os desafios, foi notável o empenho que tiveram e sempre ficavam muito orgulhosos de saber que haviam acertado a questão. Inclusive durante a realização dos desafios houve uma concorrência saudável, positiva e produtiva entre os grupos, como comprovam alguns comentários: "Foi algo diferente e bem competitivo!"; "São desafiadoras"; "Pois eram formas divertidas e interessantes de aprender o conteúdo".

$\mathrm{Na}$ etapa inicial em que os alunos foram instigados a resolverem os desafios a partir dos seus conhecimentos prévios sobre os princípios fundamentais da contagem, os subsunçores, nota-se que o trabalho em grupo foi importante para esse resgate. Neste contexto a teoria da aprendizagem de Ausubel também propõe que os conhecimentos prévios dos alunos sejam valorizados, para que possam construir estruturas mentais que permitam descobrir e redescobrir outros conhecimentos, caracterizando, assim, uma aprendizagem prazerosa e eficaz.

Na Questão 8, Gráfico 6 - Quadro 4, quando perguntados sobre se eles tinham tentado resolver os desafios, 21 alunos responderam que se empenharam em resolvê-los o 
que comprova que as atividades propostas eram desafiadoras, pois os grupos sentiam-se capazes e instigados a resolvê-los. O que provavelmente tornou a atividade prazerosa foi o fato de que os desafios abordavam temas do cotidiano dos alunos como futebol, comida e amigos.

Neste sentido, entende-se que as atividades propostas atendem o que propõe a teoria de aprendizagem significativa de Ausubel, em que uma das condições para a ocorrência da aprendizagem significativa, é que "o material a ser aprendido seja relacionável a estrutura cognitiva do aprendiz, de maneira não arbitrária e não literal. Um material com essa característica é dito potencialmente significativo”. (MOREIRA, 2011, p. 164). Ou seja, o material apresentado pode ser potencialmente significativo para o aluno.

$\mathrm{Na}$ etapa seguinte, após o estudo dos conteúdos de Análise Combinatória, os alunos resolveram exercícios e problemas. Foi observado que enquanto faziam atividades relacionadas a apenas um tipo de agrupamento, eles não apresentaram dificuldades. Em algumas situações a professora auxiliava-os, como mediadora, na interpretação do problema, pois na resolução não tinham dificuldades. Na sequência foram retomados os desafios desenvolvidos anteriormente, com o objetivo de mostrar aos alunos que esses poderiam ser resolvidos utilizando-se uma fórmula, ou seja, foi mostrado a eles que existem outras maneiras de resolver um mesmo exercício.

Observa-se que há indícios de que houve aprendizagem pois nesse caso, a experiência do aluno foi fundamental, uma vez que o início do estudo de Análise Combinatória baseou-se na resolução de problemas/desafios utilizando-se os princípios fundamentais da contagem, conhecimentos adquiridos anteriormente na sua trajetória escolar. Para que na sequência os novos conteúdos fossem aprendidos por ele e depois incorporados de forma significativa.

Também foi perguntado aos alunos se eles haviam aprendido os conteúdos de Análise Combinatória com o trabalho realizado. Como mostra o Gráfico 5 - Quadro 4, 12 alunos responderam que aprenderam muito, 12 alunos responderam que aprenderam mais ou menos e apenas 2 alunos responderam que aprenderam pouco, argumentando: "Falta de interesse da minha parte" e "Falta de atenção minha". Dos alunos que assinalaram mais ou menos, alguns também comentaram: “Umas coisas eu não entendi!", “Em algumas coisas fiquei com dúvida", "Foi possivel perceber que as vezes não precisamos usar contas, basta pensar."

Quando a aluna argumenta que basta pensar, ela deve estar se referindo a resolução dos exercícios sem aplicação de fórmulas, de forma mecânica, pois muitas vezes descrever as hipóteses do problema auxilia na estratégia para resolvê-lo. Essa ideia vai ao encontro 
do que Vazquez (2004) afirma, que "Cada um desses problemas é um desafio para os alunos, pois exige flexibilidade de pensamento: é necessário parar, concentrar, discutir e pensar para poder resolvê-los".

Apresentam-se outros comentários de alunos sobre a aprendizagem: "Aprendi muito, achei muito divertido a gente fazer os desafios sem ter visto o conteúdo, depois com a explicação a gente entendeu melhor"; "Aprendi muito, pois me desafiei, me empenhei e busquei mais conhecimentos para resolver as questões"; "Aprendi um novo jeito de resolver exercícios".

Sobre a avaliação da aprendizagem significativa, conforme Moreira (2011, p. 52), ela deve ser formativa e recursiva, "é necessário buscar evidências de aprendizagem significativa ao invés de querer determinar se ocorreu ou não”. Deste modo, nesta pesquisa, os alunos fizeram e refizeram exercícios e problemas apresentando mais de uma estratégia de solução, justificando suas respostas até elas fazerem sentido para eles.

Portanto, a partir dos comentários dos alunos, respostas ao questionário de avaliação, os avanços obtidos dos testes diagnóstico para final, pode-se concluir que, para a maioria dos alunos essa proposta de ensino foi bem-aceita, a dinâmica de trabalho e o tipo de atividade desenvolvida despertaram interesse, o que contribuiu para indícios de aprendizagem significativa.

\section{CONSIDERAÇÕES FINAIS}

Considerando o que foi exposto e analisado, observa-se que em relação aos conteúdos de Análise Combinatória, um percentual significativo dos alunos que participaram da pesquisa, apresentaram avanços na capacidade de resolver problemas sobre contagem e no desenvolvimento do raciocínio combinatório.

Pode-se dizer que a estratégia adotada de iniciar com a resolução de desafios (situações-problema), em grupo, a fim de motivá-los, bem como resgatar seus conhecimentos prévios (subsunçores) sobre os princípios fundamentais da contagem adquiridos ao longo da trajetória escolar, mostrou-se bastante positiva, apesar deles terem relatado que acharam alguns desses desafios um pouco difíceis, o que é normal.

O que contribuiu também para esse processo inicial e foi melhorando com o passar do tempo foram as discussões nos grupos. Nelas eles foram elaborando estratégias de solução para os problemas e/ou desafios propostos bem como, melhorando sua comunicação matemática. Analisando-se os diálogos registrados no diário de bordo, verificou-se que a comunicação estabelecida nos grupos ocorreu de forma contributiva. No momento da aproximação da professora a comunicação passava para um padrão reflexivo, 
pois nesse momento eram feitas perguntas aos alunos que os faziam pensar.

Quanto às estratégias utilizadas para resolver os problemas, percebe-se que foram melhorando na medida em que as discussões iam ocorrendo no grande grupo. No que se refere a resolução de problemas utilizando-se ou não as fórmulas, alguns deixaram-nas totalmente de lado e não as utilizaram para resolver as questões. Outros, por sua vez, optaram por resolver utilizando as duas maneiras, a fim de validar o resultado encontrado. Um terceiro grupo optou por resolver os problemas utilizando fórmulas, sem criar nenhuma outra estratégia. De acordo com os testes aplicados, percebe-se que houve maior êxito nos alunos pertencentes ao segundo grupo, ou seja, tiveram um maior índice de acertos. De modo geral, pode-se afirmar que o tipo de atividade proposto e a metodologia utilizada contribuiu para o desenvolvimento do pensamento combinatório.

Considerando o material apresentado, com características de ser potencialmente significativo para o aluno, a metodologia adotada, trabalho em grupo, e a análise na evolução da comunicação a partir das discussões em grupo, pode-se afirmar que há sim indícios de que, para a maioria dos alunos participantes da pesquisa houve aprendizagem significativa dos conteúdos de Análise Combinatória estudados.

\section{REFERÊNCIAS}

AUSUBEL, D. Aquisição e Retenção de Conhecimentos: Uma Perspectiva Cognitiva. Lisboa: Plátano: 2013.

BORDENAVE, Juan Diaz. O que é comunicação. São Paulo: Brasiliense, 2007.

BRASIL. Base Nacional Comum Curricular. Ensino Médio. Brasília: MEC/Secretaria de Educação Básica, 2018.

COHEN, E. G.; LOTAN, R. A. Planejando o Trabalho em Grupo. 3.ed. Porto Alegre: Penso: 2017.

JACOBY, K. O Ensino de Análise Combinatória Pautado na Aprendizagem, nos Trabalhos em Grupo e na Comunicação Matemática. 2019. 102f. Dissertação (Mestrado Profissional em Matemática em Rede Nacional - PROFMAT) - Universidade Federal da Fronteira Sul - Campus Chapecó/SC.

MARTINHO, M. H.; PONTE, J. P. da. A comunicação na sala de aula de matemática: Um campo de desenvolvimento profissional do professor. 2007. 12f. Universidade do Minho.

MASINI, E. F. S.; MOREIRA, M. A. Aprendizagem Significativa na Escola. Curitiba: CRV, 2017.

MOREIRA, M. A. Teorias de aprendizagem. 2. ed. São Paulo: EPU, 2011.

$\overline{\mathrm{LF}, 2011}$.

Aprendizagem Significativa: a teoria e textos complementares. São Paulo:

QUEIROZ, C. S. de. Trabalho em grupo trás benefícios para o aprendizado. 2015.

Disponível em: http://www.revistaeducacao.com.br/trabalho-em-grupo-traz-beneficios- 
para-o-aprendizado/ Acesso em: 28/10/2018.

SARRAMONA, J. La educación como sistema de educación. In Castillejo \& Colom, Pedagogia Sistemica. Barcelona: CEAC,1987.

VAZQUEZ, Cristiane Maria Roque. Análise Combinatória: Alguns aspectos históricos e uma Abordagem pedagógica. 2004. 13f. Artigo - Educação Matemática um compromisso social. 